\title{
The Causes and Consequences of
} miR-503 Dysregulation and Its Impact on Cardiovascular Disease and Cancer

\section{OPEN ACCESS}

Edited by:

Chiranjib Chakraborty, Adamas University, India

Reviewed by: Anatoliy Ivashchenko, Al-Farabi Kazakh National University, Kazakhstan Ana Karen González Palomo, Universidad Autónoma de San Luis Potosí, Mexico

*Correspondence: Zhengyuan Xia zyxia@hku.hk

Specialty section: This article was submitted to Experimental Pharmacology and Drug Discovery, a section of the journal Frontiers in Pharmacology

Received: 15 November 2020 Accepted: 20 January 2021 Published: 08 March 2021

Citation:

He Y, Cai Y, Pai PM, Ren X and Xia Z (2021) The Causes and Consequences of miR-503 Dysregulation and Its Impact on Cardiovascular Disease and Cancer.

Front. Pharmacol. 12:629611. doi: 10.3389/fphar.2021.629611

\begin{abstract}
Yanjing $\mathrm{He}^{1}$, Yin Cai ${ }^{2}$, Pearl Mingchu Pai ${ }^{3,4}$, Xinling $\mathrm{Ren}^{5}$ and Zhengyuan Xia ${ }^{1,6,7 *}$
${ }^{1}$ Department of Anesthesiology, The University of Hong Kong, Hong Kong, China, ${ }^{2}$ Department of Health Technology and Informatics, The Hong Kong Polytechnic University, Hong Kong, China, ${ }^{3}$ Department of Medicine, The University of Hong Kong Shenzhen Hospital, Shenzhen, China, ${ }^{4}$ Department of Medicine, The University of Hong Kong - Queen Mary Hospital, Hong Kong, China, ${ }^{5}$ Department of Respiratory Medicine, Shenzhen University General Hospital, Shenzhen, China, ${ }^{6}$ State Key Laboratory of Pharmaceutical Biotechnology, Department of Medicine, The University of Hong Kong, Hong Kong, China, ${ }^{7}$ Department of Anesthesiology, Affiliated Hospital of Guangdong Medical University, Zhanjiang, China
\end{abstract}

microRNAs (miRs) are short, non-coding RNAs that regulate gene expression by mRNA degradation or translational repression. Accumulated studies have demonstrated that miRs participate in various biological processes including cell differentiation, proliferation, apoptosis, metabolism and development, and the dysregulation of miRs expression are involved in different human diseases, such as neurological, cardiovascular disease and cancer. microRNA-503 (miR-503), one member of miR-16 family, has been studied widely in cardiovascular disease and cancer. In this review, we summarize and discuss the studies of miR-503 in vitro and in vivo, and how miR-503 regulates gene expression from different aspects of pathological processes of diseases, including carcinogenesis, angiogenesis, tissue fibrosis and oxidative stress; We will also discuss the mechanisms of dysregulation of miR-503, and whether miR-503 could be applied as a diagnostic marker or therapeutic target in cardiovascular disease or cancer.

Keywords: microRNAs, microRNA-503, cardiovascular disease, cancer, angiogenesis, oxidative stress

\section{INTRODUCTION}

microRNAs (miRs) are small non-coding RNAs with 19-23 nucleotides ( $\mathrm{nt}$ ) in length that modulate target genes through mRNA degradation or translational repression (Bartel, 2004; Ahmed et al., 2018). miRs biogenesis includes canonical and non-canonical pathways, and has been summarized in several reviews (Bartel, 2004; O'Brien et al., 2018). miR genes are transcribed by RNA polymerase II to generate primary miR transcripts (pri-miRs), which is cleaved by RNase III endonuclease Drosha to produce about 60-70 nt stem loop intermediate, termed miR precursor, or the pre-miR. The premiR is transported by Ran-GTP and export receptor Exportin-5 from nucleus to the cytoplasm. In canonical pathway of miRs genesis, pre-miR is processed by another RNase III endonuclease, Dicer, to produce miR:miR duplex comprising the mature miR strand and its complementarystrand. The mature miR is loaded into the cytoplasmic RNA-induced silencing complex (RISC) where it binds to the $3^{\prime}$-untranslated region (UTR) of target mRNAs with complementary sites, resulting in mRNA degradation or its translational repression.

miRs are implicated in various biological processes, including cell differentiation (Chen et al., 2004), proliferation, apoptosis (Brennecke et al., 2003), metabolism (Joacim et al., 2008), and 
development (Gerhard et al., 2006), and in pathological situations like hypoxic cellular injury and repairing (Chen et al., 2013; Ge L. et al., 2019). Over $1 / 3$ of human protein-coding genes are modulated by miRs (Lewis et al., 2005). Growing evidence has demonstrated that numerous miRs are dysregulated in human diseases. Some miRs are upregulated, such as miR-25 in heart failure (Christine et al., 2014), miR-133a in acute myocardial infarction (Wang et al., 2013), miR-155-5p in chronic kidney disease and nocturnal hypertension (Klimczak et al., 2017) are enhanced, while some miRs are downregulated in other diseases, such as miR-320a in arrhythmogenic cardiomyopathy (Sommariva et al., 2017), both miR-133 and miR-1 in hypertrophic cardiomyopathy (Alessandra et al., 2007), miR107 in Alzheimer's disease (Wang et al., 2008), and miR-503$5 p$ in non-small cell lung cancer (Yang et al., 2014) are reduced. Therefore, therapies that inhibit miR function or restore its function have been developed for human diseases (Couzin, 2008; Manel, 2011).

microRNA-503 (miR-503) is an intragenic miR located on the chromosomal location Xq26.3 and clustered with miR-424 in human (Griffiths-Jones et al., 2008). It belongs to the miR-16 family (Caporali and Emanueli, 2011), and was first identified in human retinoblastoma tissues by microRNA microarray analysis (Zhao et al., 2009). The other members of miR-16 family are miR15a, miR-15b, miR-16, miR-195, miR-424 and miR-497, miR-16 family have similarity in their individual seed sequences (Caporali and Emanueli, 2011). According to gene nomenclature, in human, there are two different mature miR-503, one is hsamiR-503-5p, derived from $5^{\prime}$ ends of pre-miR-503, the other is hsa-miR-503-3p, derived from $3^{\prime}$ ends of pre-miR-503, both are excised from the same precursor microRNA (Griffiths-Jones et al., 2006), and thus, miR-503 rather than miR-503-5p is usually used. Although these " $5 p$ " and " $3 p$ " miRs are originated from a single primary transcript, they have different sequences and mRNA targets, therefore, they have different, even converse roles in biological function (Almeida et al., 2012). Accumulated evidence has also shown that miR-503 modulates various biological processes, and the dysregulation of miR-503 is associated with human diseases. In this review, we will mainly focus on describing the roles of miR-503 in human diseases, especially cardiovascular disease and cancer, from different aspects of physiological or pathological processes, including cell differentiation, proliferation, apoptosis, carcinogenesis, angiogenesis, tissue fibrosis and oxidative stress.

\section{Physiological Roles of miR-503 in Regulating Cell Differentiation}

The relationship between cell proliferation and cell differentiation is complicated, and the imbalance of cell proliferation and differentiation can result in a variety of diseases such as cancer (Ruijtenberg and van Den Heuvel, 2016). MiR-424/-503 was found to a polycistronic microRNA cluster, the loci of them were separated by 383 bases on the genome (Forrest et al., 2009). In the differentiation of monoblasts into monocytes, overexpression of either miR-424 or miR-503 can induce cell cycle arrest at G1 phase by targeting an anti-differentiative miR- 9 and several regulators of cell cycle, therefore, both miR-424 and miR-503 can partially promote monocytic differentiation and inhibit cell proliferation at G1 phase in the cell cycle (Forrest et al., 2009). Consistent with this, induction of G1 phase cell cycle arrest, which is mainly caused by the suppression of cyclindependent-kinase 2 (cdk2), is a critical step during myogenesis (Sarkar et al., 2010). miR-424 and miR-503 were induced in the differentiation of myoblasts into myotubes and promotedcdk2 inhibition by downregulating Cdc25A (Sarkar et al., 2010). Cdc25A, a phosphatase that is the target gene of both miR424 and miR-503, can get rid of the inhibitory phosphorylation on cdk2, and thus promote cell cycle progress (Sarkar et al., 2010). In another study, miR-322/-503 cluster was found to be abundantly expressed in the earliest mice cardiac progenitor cells, it induced cardiac and skeletal muscle cell differentiation but inhibited neural lineages, which is likely mediated by targeting the RNA-binding protein CUG-binding protein Elavlike family member 1 (Shen et al., 2016). Taken together, miR-503 is a regulator in cell differentiation.

\section{miR-503 Expression Level and Its Molecular Targets During Cell Proliferation and Apoptosis}

miRs have been demonstrated to regulate cell proliferation and apoptosis. Here, studies of miR-503 in regulating cell proliferation or apoptosis in vitro are summarized and listed in Table 1.

In human aortic smooth muscle cells (SMCs), treatment with platelet-derived growth factor (PDGF) reduced miR-503 expression level significantly in a dose and time-dependent manner, while overexpression of miR-503 inhibited SMCs proliferation and migration induced by PDGF, miR-503 played this role by downregulating its target insulin receptor (Bi et al., 2016). Carotid artery stenosis (CAS) is a kind of atherosclerotic vascular disease, and the abnormal cell proliferation of vascular SMCs is related with the occurrence of CAS (Faxon et al., 2004). Yan et al., (2020) reported that plasma level of miR-503 in asymptomatic patients with CAS was lower compared with that in healthy individuals, and they also demonstrated that overexpression of miR-503 in vascular SMCs in vitro inhibited cell proliferation, and miR-503 inhibitor counteracted this effect. It is concluded that miR-503 can be a potential diagnostic marker for CAS and that miR-503 overexpression may improve CAS by inhibition of cell proliferation of vascular SMCs (Yan et al., 2020). However, Cremer et al., (2019) reported that long noncoding RNA (lncRNA) MALAT1 (metastasis-associated lung adenocarcinoma transcript 1) expression level was reduced in atherosclerotic vessels of symptomatic patients, and that transplantation of MALAT1-deficient bone marrow cells in apolipoprotein E-deficient $\left(\mathrm{Apoe}^{-/-}\right)$mice promoted atherosclerosis in vivo, the MALAT1 targets including miR503 in Apoe $^{-/-}$Malat1 $^{-/-}$bone marrow cells were increased. In animal model of atherosclerosis, miR-503 was also increased in aortic roots of $\mathrm{Apoe}^{-/-} \mathrm{Malat}^{-/-}$mice, and inhibition of miR-503 in vitro in bone marrow mononuclear cells from $\mathrm{Apoe}^{-/-}$ Malat $1^{-/-}$mice reduced cell adhesion to endothelial cells 
TABLE 1 | Roles of miR-503 in cells and its targets.

\begin{tabular}{|c|c|c|c|}
\hline miRs & Cell types & Identified targets & References \\
\hline miR-503-5p & Human aortic SMCs & INSR & Bi et al., (2016) \\
\hline miR-503-5p & ECSCS & Cyclin D1, Bcl-2, VEGFA and ROCK1 & Hirakawa et al., (2016) \\
\hline miR-503-5p & EPCs & Apelin & Wen et al., (2018) \\
\hline miR-503-5p & BMDCs & $\mathrm{Bcl}-2$ & Min et al., (2013) \\
\hline miR-503-3p & Lung cancer cells & p21 & Sun et al., (2017) \\
\hline miR-503-5p & Podocytes & E2F3 & Zha et al., (2019) \\
\hline miR-503-5p & HMEC & Apelin-12 & Chen et al., (2020) \\
\hline
\end{tabular}

pre-stimulated by tumor necrosis factor- $\alpha$ (TNF- $\alpha$ ). However, whether overexpression or inhibition of miR-503 can alleviate atherosclerosis needs further studies in vivo.

In human endometriotic cyst stromal cells (ECSCs) (Hirakawa et al., 2016), the expression level of miR-503 was downregulated due to DNA hypermethylation, and miR-503 overexpression in ECSCs resulted in inhibition of cell proliferation, induction of cell apoptosis and reduction of extracellular matrix (ECM) contractility by suppressing its targets cyclinD1, B-cell lymphoma/leukemia-2 (Bcl-2), Ras homology A (RhoA), Rhoassociated coiled-coil-forming protein kinase (ROCK1), ROCK2 and vascular endothelial growth factor A (VEGFA) (Hirakawa et al., 2016). In murine bone marrow-derived dentritic cells (BMDCs) (Min et al., 2013), some miRs including miR-503, miR-21, miR-155, miR-146a, miR-142, miR-22 and miR-16-1 were elevated when BMDCs were cocultured with tumor cells, and miR-503 downregulated the expression level of its target Bcl2 at transcript and protein levels, leading to BMDCs apoptosis, while inhibition of miR-503 prolonged BMDCs lifespan, and thus may improve antitumor response in BMDCs.

Under hypoxia condition, the role of miR-503 is inconsistent in different cell types (Keighron et al., 2018; Wen et al., 2018). For instance, Endothelial progenitor cells (EPCs) are a kind of blood cells which have the characteristics of vascular regeneration (Keighron et al., 2018). In mouse bone marrow derived EPCs, miR-503 was downregulated under hypoxia condition (Wen et al., 2018), and its overexpression inhibited cell proliferation, migration and angiogenesis of EPCs via regulating its target Apelin, which is encoded by APLN gene. APLN gene encodes preproapelin, then preproapelin is cleaved to several apelin peptides including apelin-36, -17, -12, and -13 (Wysocka et al., 2018). However, in bone marrow-derived mesenchymal stem cells, Nie et al., (2011) reported that miR-503 was upregulated following $6 \mathrm{~h}$ of hypoxia stimulation, inhibition of miR-503 aggravated mesenchymal stem cells apoptosis.

In non-small cell lung cancer (NSCLC) cell lines, Sun et al., (2017) demonstrated that overexpression of miR-503-3p suppressed cell proliferation and induced cell apoptosis via downregulating its target p21. p21 is one of cyclin dependent kinase inhibitor proteins (CDKIs) which include Ink4 family and KIP family (Watanabe et al., 1998). However, Chen et al., (2017) reported that long non-coding RNA SNHG20 promoted cell proliferation of NSCLC cell lines partly by downregulating p21 expression. Zhang and Yan (2012) reported that carboxylated multiwalled carbon nanotubes (MWCNTs) treatment inhibited cell proliferation and induced p 21 protein overexpression in cells without detectable DNA damage and apoptosis, and the upregulated p21 protein inhibited the function of cyclin $\mathrm{D} / \mathrm{cdk} 4,6$ complex, then inactivated retinoblastoma (Rb) phosphorylation leading to cell cycle arrest at G1/S phase. In mouse embryonic fibroblasts $\mathrm{p} 21^{-1-}$ cells, MWCNTs treatment didn't induce cell cycle arrest at G1/S phase (Zhang and Yan, 2012). From Sun Y et al.'s study (Sun et al., 2017), it is inferred that the downregulation of p21 mediated by miR-503-3p in NSCLC cell lines can inhibit cell proliferation and promote cell apoptosis. However, Chen ZY et al.'s study (Chen et al., 2017) indicated that the downregulation of p 21 mediated by SNHG20 in NSCLC cell lines promoted cell proliferation. While Zhang Y et al.'s study (Zhang and Yan, 2012) inferred that upregulation of p21 can inhibit cell proliferation. Thus, p21 has a dual role in cell proliferation and apoptosis, and this dual role depends on its cellular localization, and p21 regulation of cell proliferation and apoptosis has been extensively reviewed elsewhere (Kreis et al., 2019; Manu et al., 2019). The inconsistent role of p21 mediated by miR-503-3p or SNHG20 in NSCLC cell lines may be due to the different cell lines used. However, the inconsistency from these studies needs to be investigated further.

In podocytes, high glucose (HG) treatment increased miR-503 expression level in a time and dose-dependent manner and decreased E2F transcription factor 3 (E2F3) expression level (Zha et al., 2019). miR-503 overexpression increased podocytes apoptosis, while its inhibition improved renal function in rats of Diabetes mellitus via targeting E2F3 (Zha et al., 2019). In human microvascular endothelial cells (HMEC-1) (Chen et al., 2020), HG treatment also increased miR-503 expression level markedly, but decreased the expression of Apelin-12, which was proven to be a miR-503 target by luciferase assay. miR-503 inhibited Apelin-12 expression, while it up-regulated the phosphorylation of JNK and p38MAPK. In contrast, inhibition of miR-503 alleviated oxidative stress, inflammation and apoptosis induced by HG in HMEC-1 cells (Chen et al., 2020). The expression level of miR-503 induced by HG in both types of cells is consistent, and the increase of miR-503 contributes to cell apoptosis under HG condition.

\section{Roles of miR-503 in Carcinogenesis}

Accumulated evidence has shown that miR-503 is implicated in carcinogenesis and angiogenesis. Uncontrolled angiogenesis contributes to tumor growth and invasiveness (Peter and Rakesh, 2011). miR-503 expression is dysregulated in tumor or cancer. In this section, we summarize the related findings of 
TABLE 2 | The expression level and targets of miR-503 in cancer.

\begin{tabular}{|c|c|c|c|c|}
\hline miRs & Cancer types & Upregulated $\uparrow /$ downregulated $\downarrow$ & Identified targets & References \\
\hline miR-503-5p & $\mathrm{HCC}$ & $\downarrow$ & FGF2, VEGFA & Zhou et al., (2013) \\
\hline miR-503-5p & $\mathrm{HCC}$ & $\downarrow$ & Cyclin D3, E2F3 & Xiao et al., (2013) \\
\hline miR-503-5p & NSCLC & $\downarrow$ & PI3K p85, IKK- $\beta$ & Yang et al., (2014) \\
\hline miR-424/-503 & Breast cancer & NA & Smad7, Smurf2 & Li et al., (2014) \\
\hline miR-503-5p & Breast cancer & $\downarrow$ & IGF-1R & Yan J. et al., (2017) \\
\hline miR-503-5p & Breast cancer & $\downarrow$ & CCND1 & Long et al., (2015) \\
\hline$m i R-503-3 p$ & Breast cancer & $\uparrow$ & Smad2, E-cadherin & Zhao et al., (2017) \\
\hline miR-503-5p & $\mathrm{CC}$ & $\downarrow$ & AKT2 & Fu et al., (2019) \\
\hline miR-503-5p & Prostate cancer & $\downarrow$ & ZNF217 & Jiang et al., (2016) \\
\hline miR-503-5p & GBM & $\downarrow$ & IGF-1R & Zhang et al., (2014) \\
\hline miR-503-5p & GBM & $\uparrow$ & PDCD4 & Guo et al., (2017) \\
\hline miR-503-5p & $\mathrm{CRC}$ & $\downarrow$ & E2F3 & Chang et al., (2015) \\
\hline$m i R-503-5 p$ & $\mathrm{CRC}$ & $\uparrow$ & CaSR & Noguchi et al., (2016) \\
\hline miR-503-5p & $\mathrm{GC}$ & $\downarrow$ & HMGA2 & Li et al., (2019) \\
\hline$m i R-503-5 p$ & Osteosarcoma & $\downarrow$ & IGF-1R & Wang et al., (2017) \\
\hline miR-503-5p & ESCC & $\uparrow$ & PRKACA & Wu et al., (2018) \\
\hline miR-503-5p & Retinoblastoma & $\uparrow$ & PTPN12 & Cheng and Liu (2019) \\
\hline
\end{tabular}

NA, Not applicable.

miR-503 in cancer and list in Table 2. The role of miR-503 in angiogenesis will be discussed in the next section.

PI3K/Akt signaling pathway plays an important role in cell growth and cell survival (Cantley, 2002). Phosphionositide 3kinaes (PI3Ks) consists of catalytic subunits and regulatory subunits, and PI3Kp85 is one of the regulatory subunits (Fruman et al., 1998). In human NSCLC, miR-503 expression level was downregulated in lung cancer tissues compared with adjacent non-cancerous tissues (Yang et al., 2014), while its overexpression impeded tumor growth, metastasis and cell proliferation in a xenografted mice model, and in NSCLC cell lines. Both PI3Kp85 and IKK- $\beta$ were proven as direct targets of miR-503 by luciferase assay (Yang et al., 2014). IKB kinase $\beta$ (IKK- $\beta$ ) has been shown to link inflammation to cancer, and deletion of IKK- $\beta$ can reduce colitis-associated tumor incidence and attenuate tumor growth (Greten et al., 2004). In NSCLC, miR-503 might act as a tumor suppressor by downregulating its targets PI3K p85 and IKK- $\beta$ (Yang et al., 2014).

In human hepatocellular carcinomas (HCC) tumor, two studies have consistently reported that miR-503 expression level was downregulated in tumor tissues compared with matched adjacent normal tissues (Xiao et al., 2013; Zhou et al., 2013), and miR-503 was also downregulated in HCC cell lines compared with normal liver cell line L02 (Xiao et al., 2013), its down-regulation may be due to epigenetically modulation of the promoter of miR-503 (Zhou et al., 2013). The down-regulation of miR-503 was correlated with the low survival rate of HCC patients (Xiao et al., 2013). Overexpression of miR-503 impeded tumor growth and angiogenesis in a hepatoma xenograft mouse model (Zhou et al., 2013). In vitro, miR-503 overexpression repressed human umbilical vein endothelial cells (HUVECs) capillary tube formation, HCC cell proliferation and colony formation, and induced cell cycle arrest at G1 phase in HCC cells through inhibiting its targets, fibroblast growth factorb (FGF2), VEGFA, cyclin D3 and E2F3 (Xiao et al., 2013; Zhou et al., 2013).
In breast cancer, the reports about miR-503 expression level from different cancer stages are inconsistent. Li et al., (2014) found that miR-424/-503 cluster was significantly higher in breast cancer tissues from patients with metastasis than that without metastasis. Smad7 and Smurf2 are inhibitory factors of transforming growth factor beta (TGF- $\beta$ ), and the targets of miR-424/-503 cluster. Overexpression of this cluster suppressed Smad7 and Smurf2 expression and activated TGF$\beta$ signaling, promoting breast cancer cells metastasis in nude mice, while inhibition of miR-424/-503 cluster in breast cancer cells attenuated metastasis in nude mice and improved host survival, suggesting that miR-424/-503 cluster act as "onco$m i R$ " in breast cancer. However, in another two studies, miR503 in cancer tissues or cells was shown to be reduced remarkably compared to adjacent non-cancerous tissues and non-malignant breast epithelial cells (Long et al., 2015; Yan J. et al., 2017). Moreover, miR-503 was lower in T2-T4 stage of breast cancer than that in T1 stage (Yan J. et al., 2017). Overexpression of miR503 impeded breast cancer cell proliferation and invasion through inhibiting its target genes Insulin-like growth factor 1 receptor (IGF-1R) (Yan J. et al., 2017) and CCND1 (encoding cyclin D1) (Long et al., 2015). IGF-1R belongs to IGF receptor family, and IGF-1R signaling pathway participates in tumor growth and metastasis (Tognon and Sorensen, 2012). Therefore, the inconsistence of miR-503 expression level in different stages of breast cancer needs more evidences, the effects of its overexpression or inhibition in breast cancer on metastasis deserve further investigation.

In breast cancer, miR-503-3p expression level was found to be higher in cancer tissues and plasma of patients compared with adjacent normal tissues and plasma of healthy subjects, and the high level of miR-503-3p was correlated with breast cancer metastasis (Zhao et al., 2017). Smad2 and E-cadherin were proven as miR-503-3p targets by luciferase assay, and the mRNA levels of both Smad2 and E-cadherin were lower in cancer tissues of patients compared with adjacent normal tissues, and it has been demonstrated in vitro that miR-503-3p 
promotes Epithelial-mesenchymal transition (EMT) and tumor metastasis by downregulation of Smad2 and E-cadherin. Tumor metastasis is a complicated process, it contains EMT and Mesenchymal-epithelial transition (MET). E-cadherin is one of EMT markers, and loss of this protein promotes metastasis (Heerboth et al., 2015). Smads family are intracellular effectors of the TGF-beta superfamily, and Smad2 is one member of Receptor Activated Smads family (Hanna et al., 2021).

In cervical cancer (CC), the expression level of miR-503 in cancer tissues of patients was downregulated compared with adjacent normal tissues, and overexpression of miR-503 in CC cell lines inhibited cell proliferation and colony formation by targeting AKT2, while miR-503 inhibitor reversed these effects (Fu et al., 2019). The mRNA expression level of AKT2 is higher in cancer tissues than that in adjacent normal tissues, and it was proven as miR-503 target by luciferase assay. AKT2 is one isoform of AKT (also called protein kinase $\mathrm{B}$ ), and activation of AKT promotes cell proliferation and survival (Osaki et al., 2004). Thus, miR-503 may act as a tumor suppressor in CC (Fu et al., 2019). In prostate cancer, miR-503 expression level was also downregulated in cancer tissues of patients compared with adjacent normal tissues (Jiang et al., 2016), its down-regulation was associated with invasive features and poor prognosis in prostate cancer patients. GATA binding protein 3 (GATA3) is a zinc-binding transcription factor, it is found to bind the promoter of miR-503 and activate miR-503 transcription, however, GATA3 expression was also decreased remarkably in prostate cancer tissues. Zinc finger protein 217 (ZNF217) was proven as miR-503 target, it is demonstrated that GATA3/miR503 axis suppressed the progression of prostate cancer by inhibiting ZNF217 expression.

In human glioblastoma multiforme (GBM), Zhang et al., (2014) found that miR-503 expression level was reduced markedly in GBM tissues and cells compared with human normal brain tissues from patients with cerebral trauma, its overexpression in GBM cells impeded cell proliferation, migration and tumor invasion, and increased cell apoptosis. They further demonstrated that miR-503 acted as tumor suppressor in GBM partially by downregulating its target IGF$1 \mathrm{R}$ and interfering with PI3K/AKT pathway. However, Guo et al., (2017) found that the expression level of miR-503 was elevated in glioblastoma tissues or cancer cells compared to normal human brain tissue and normal human astrocytes separately. And they showed that overexpression of miR-503 in glioblastoma cells increased cell proliferation, and reduced cell apoptosis by targeting PDCD4 (programmed cell death 4). By contrast, inhibition of miR-503 impeded cell proliferation (Guo et al., 2017). PDCD4 is known as one tumor suppressor gene which inhibits cell proliferation, tumor angiogenesis and induces apoptosis (Lankat-Buttgereit and Goke, 2009). Zhang et al., (2014) compared miR-503 expression level in cancer cells with that in normal brain tissues and found that miR-503 was downregulated, Guo et al., (2017) did not describe clearly from where the normal human brain tissue was obtained. Thus, the inconsistent expression level of miR-503 between these two studies may be due to the source of control samples.
Also, the function of miR-503 in glioblastoma between both studies is inconsistent, this needs to be investigated further.

In colorectal cancer (CRC), the role of miR-503 is also inconsistent. Chang et al., (2015) reported that miR-503 expression level was reduced remarkably in cancer tissues or cells compared with adjacent normal tissues and normal colonic cell line separately, its overexpression in CRC cells suppressed cell proliferation and increased cell apoptosis rate by targeting E2F3. Whereas in Noguchi et al.'s study (Noguchi et al., 2016), in normal mucosa, colorectal adenoma and cancer tissues, the expression level of miR-503 was increased in sequence from adenoma to carcinoma, higher miR-503 expression in patients was related with large tumor size, tumor invasion and metastasis, and inhibition of miR-503 in CRC cells suppressed cell proliferation, invasion and migration, which is suggestive that miR503 acted as an "onco-miR" in CRC by downregulation of calcium-sensing receptor (CaSR) expression. CaSR is a $\mathrm{G}$ proteincoupled receptor and functions as a tumor suppressor in colon cancer (Singh et al., 2013). Therefore, the expression level and function of miR-503 in CRC is inconsistent. In Noguchi et al.'s study, the control samples were from healthy volunteers, while in Chang et al.'s study, the control samples were from adjacent normal tissues of cancer patients, this may explain the inconsistence of miR-503 expression. Nonetheless, the function of miR-503 in CRC deserves further investigation.

In other gastrointestinal cancer, such as gastric cancer (GC) (Li et al., 2019) and esophageal squamous cell carcinoma (ESCC) (Wu et al., 2018), the miR-503 expression level is converse. miR503 expression decreased remarkably in tissues of GC, but highly expressed in tissues of ESCC, as compared with individual adjacent non-cancerous tissues (Wu et al., 2018; Li et al., 2019), while it was lower in tissues of ESCC with metastasis than that without metastasis (Wu et al., 2018). In GC, overexpression of miR-503 impeded cell proliferation, invasion and colony formation in vitro and tumor growth in vivo by suppressing target gene HMGA2 (encoding High-mobility group AT-hook 2) and WNT/ $\beta$-catenin signaling pathway (Li et al., 2019). Ectopic expression of miR-503 in ESCC cells also impeded cell proliferation, invasion and metastasis by inducing cellular autophagy in vitro and in vivo. Protein kinase cAMP-activated catalytic subunit alpha (PRKACA) was proven as miR-503 target gene by luciferase assay, and it is suggested that miR-503 induced autophagy in ESCC cells via the protein kinase A (PKA)/ mammalian target of rapamycin (mTOR) pathway (Wu et al., 2018).

In osteosarcoma, miR-503 expression level was reduced in tumor tissues compared with matched adjacent normal tissues, and it was lower in specimens from patients of T3-T4 stage than that of T1-T2 stage (Wang et al., 2017). In vitro, miR-503 was also lower in osteosarcoma cells than that in normal osteoblasts cells, and overexpression of miR-503 suppressed the proliferation and invasion of osteosarcoma U2OS cells, thus, it acted as a tumor suppressor in osteosarcoma via inhibiting its target, IGF-1R. However, in retinoblastoma (RB) (Cheng and Liu, 2019), miR503 was greatly expressed in RB tissues, and acted as an "oncomiR" by targeting PTPN12. 
Taken together, miR-503 expression level varies in different types of cancer. However, except for the inconsistent results of colorectal cancer and glioblastoma multiforme, miR-503 has been found to be downregulated in most of cancer types, but upregulated in few cancer types, such as retinoblastoma (Zhao et al., 2009; Cheng and Liu, 2019), ESCC (Wu et al., 2018) and adrenocortical carcinoma (Ozata et al., 2011). miR-503 can act as "onco-miR" or tumor suppressor in different types of cancer. The expression level and targets of miR-503 in cancer are listed in Table 2.

\section{Roles of miR-503 in Angiogenesis}

Numerous miRNAs, such as miR-92a (Bonauer et al., 2009), miR$29 \mathrm{~b}$ (Li et al., 2017), and miR-21 (Liu et al., 2016), are demonstrated to regulate angiogenesis, and have the characteristics of anti- or pro-angiogenesis. The miR-16 family in angiogenesis and diabetes has been reviewed elsewhere (Caporali and Emanueli, 2011). In this section, we focus on studies of miR-503 in angiogenesis.

The role of miR-503 in angiogenesis has been demonstrated in vitro and in vivo (Caporali et al., 2011; Jongmin et al., 2012; Zhou et al., 2013; Caporali et al., 2015; Wen et al., 2018). In EPCs (Wen et al., 2018), miR-503 suppressed angiogenesis by targeting Apelin. In Diabetes mellitus, miR-503 expression level was significantly higher in ischemic muscles and plasma from patients with limb ischemia than normal control (Caporali et al., 2011), and it is also higher in the plasma of diabetic patients with ischemic stroke than that in non-diabetic patients with stroke or in control individuals (Sheikhbahaei et al., 2019). Overexpression of miR-503 suppressed endothelial cells proliferation, migration and network formation by suppression of its targets, cdc25A (cell division cycle $25 \mathrm{~A}$ ) and CCNE1 (cyclin E1) under normal culture condition (Caporali et al., 2011). In diabetic mice with limb ischemia, antagonizing miR-503 improved angiogenesis and blood flow recovery by upregulating cdc25A and CCNE1 (Caporali et al., 2011). Furthermore, it was found that p75 neurotrophin receptor (p75 ${ }^{\mathrm{NTR}}$ ) activated NF- $\kappa B$ to bind the promoter of miR-503 and activated its expression in endothelial cells exposed to high glucose (Caporali et al., 2015). p75 ${ }^{\mathrm{NTR}}$ is a multifunctional membrane receptor of nerve growth factor (Caporali and Emanueli, 2009).The microparticles carrying miR-503 were shed from diabetic endothelial cells and transferred into recipient pericytes, where miR-503 inhibited pericyte migration and proliferation by targeting EFNB2 (encoding Ephrin-B2) and VEGFA, and subsequently increased vascular permeability and blocked angiogenesis in post-ischemic limb muscles of diabetic mice (Caporali et al., 2015).

In hepatocellular carcinomas (Zhou et al., 2013), miR-503 inhibited tumor angiogenesis by down-regulation of FGF2 and VEGFA. The VEGF family and FGF superfamily are regulators in angiogenesis (Peter and Rakesh, 2011), VEGF (also known as VEGFA) is a predominant regulator in the process of angiogenesis, which stimulates angiogenesis via VEGF receptor-2, thus, blockers of VEGF is widely used as an antiangiogenic agent (Peter and Rakesh, 2011). In glioma cells, overexpression of miR-503 reduced both LRIG2 (Leucine-rich repeats and immunoglobulin-like domains protein 2) and VEGFA expression levels (Sun et al., 2019), and suppressed angiogenesis in cocultured human cerebral microvascular endothelial cell line D3 (HCMEC/D3), while miR-503 inhibitor promoted angiogenesis in cocultured HCMEC/D3. LRIG2 was proven as miR-503 target by luciferase assay, knockdown of LRIG2 reduced VEGFA expression level along with the condition of miR-503 inhibitor, therefore, miR-503 regulated angiogenesis in glioma by reducing LRIG2 expression followed by downregulation of VEGFA expression (Sun S. et al., 2019). LRIG2 belongs to the leucine-rich repeats and immunoglobulin-like domains family and regulates epidermal growth factor receptor (EGFR) signaling pathway (Simion et al., 2014), and downregulation of LRIG2 suppressed angiogenesis in glioma (Yang et al., 2017). In pulmonary arterial hypertension (Jongmin et al., 2012), both hsa-miR-424 and hsa-miR-503 were decreased in pulmonary artery endothelial cells derived from patients with pulmonary arterial hypertension, and overexpression of both miRs in animal models of pulmonary hypertension can alleviate pulmonary hypertension by downregulation of FGF2 and FGF receptor (FGFR1) (Jongmin et al., 2012).

In chronic obstructive pulmonary disease (COPD) (Jun et al., 2017), miR-503 was decreased in lung fibroblasts from COPD patients, VEGF released by lung fibroblasts from patients with COPD were higher compared with that from patients without $\mathrm{COPD}$, it is inferred that miR-503 may regulate fibroblastmediated vascular homeostasis in COPD via VEGF signaling, given that VEGF plays an important role in regulating vascular homeostasis in various pathological conditions (Tsai et al., 2009; Liu et al., 2019a). In another clinical trial (Fei et al., 2018), patients with coronary artery disease (CAD) were divided into good coronary collateral circulation (CCC) formation group and poor CCC formation group, and the level of miR-503 in the plasma from good CCC or poor CCC group was lower compared with that from control subjects, and miR-503 was negatively correlated with CCC formation and VEGFA (Fei et al., 2018). This indicates that miR-503 might suppress CCC formation, and the downregulation of miR-503 in CAD patients may be a compensatory effect of protection.

Overall, the role of miR-503 in angiogenesis is consistent in different studies, and it shows the characteristic of antiangiogenesis.

\section{Roles of miR-503 in Tissue Fibrosis}

Fibrosis can a significant pathological state in many organs, such as heart (Gao et al., 2012; Liu et al., 2017; Ge Z. D. et al., 2019), lung (Yang et al., 2020), kidney and liver, and may result in the distortions of organ structure and organ dysfunction (Li et al., 2016; Warisara et al., 2020). Pro-fibrotic mediator TGF- $\beta$ (Guo et al., 2010) and its signaling pathways play an important role in the process of epithelial-mesenchymal transition and tissue fibrosis (Li et al., 2016; Warisara et al., 2020). Multiple miRs are involved in fibrosis, for instance, miR-21 stimulated the development of lung fibrosis (Liu et al., 2010), while miR-101 inhibited cardiac fibrosis after myocardial infarction (MI) (Pan et al., 2012). Several studies reported that miR-503 was implicated 
in fibrosis (Zhou et al., 2016; Yan W. et al., 2017), in this section, we list the alterations of miR-503 in fibrosis and discuss how miR503 regulates fibrosis in lung or heart.

Cardiac fibrosis can lead to contractile dysfunction (Xia et al., 2007; Gao et al., 2012; Li et al., 2015) and cardiac arrhythmia (Warisara et al., 2020). In mouse heart tissues of cardiac fibrosis induced by transverse aortic constriction (TAC) and mouse neonatal cardiac fibroblasts (CFs) cultured with Angiotensin II (Zhou et al., 2016), miR-503 expression level was upregulated, its overexpression in neonatal CFs increased cell proliferation and collagen production mediated by Angiotensin II, while pretreatment with Apelin-13 and co-transfection of miR-503 in neonatal CFs resulted in inhibition of TGF- $\beta$ and connective tissue growth factor (CTGF) expression and collagen production, Apelin-13 treatment alone decreased cell proliferation and collagen production, and reduced TGF- $\beta$ and CTGF expression levels in neonatal CFs mediated by Angiotensin II (Zhou et al., 2016). Apelin-13 was identified as target of miR503 by luciferase assay, and antagomiR-503 treatment in TAC mice improved cardiac function and suppressed both TGF- $\beta$ and CTGF expression, therefore, miR-503 has the property of promoting cardiac fibrosis in TAC mouse model. In contrary, in mouse model of pulmonary fibrosis induced by silica (Yan W. et al., 2017), miR-503 was reduced in fibrotic lung tissue and cells exposed to silica compared with control, but long non-coding RNA MALAT1 was upregulated, and MALAT1 regulated miR503 expression by competitively binding to miR-503. Snail is a transcription factor and recognized as inducer of EMT (Kalluri and Weinberg, 2009). PI3K p85 was also proven as miR-503 target, and the activation of PI3Kp85/Akt/mTOR/Snail pathway facilitated the development of EMT and pulmonary fibrosis (Yan W. et al., 2017), overexpression of miR-503 has been shown to inhibit silica-induced pulmonary fibrosis by inactivating that pathway (Yan W. et al., 2017).

From those studies, it is inferred that miR-503 attenuates pulmonary fibrosis, while it promotes cardiac fibrosis, thus the findings regarding the function of miR-503 in fibrosis is contradictory, which may be due to differences in the process of pulmonary fibrosis and cardiac fibrosis. EMT plays an critical role in the pathogenesis of pulmonary fibrosis (Heise et al., 2011), some epithelial cells in the lung can be transformed to fibroblasts by EMT (Kim et al., 2006). It is notable that there are no epithelial cells in the heart tissue, however, endothelial-to mesenchymal transition (EndMT) can be induced in the heart after MI, and EndMT becomes the source of myofibroblasts and promotes the production of fibroblastic content (Aisagbonhi et al., 2011).The molecular mechanism whereby miRs regulate tissue fibrosis formation is complicated and needs further study.

\section{Roles of miR-503 in Oxidative Stress}

Oxidative stress occurs when excessive generation of reactive oxygen species (ROS) exceeds antioxidant defense systems (González-Montero et al., 2018; Liu et al., 2020a; Liu et al., 2020b). ROS include superoxide anion $\left(\mathrm{O}_{2}{ }^{-}\right)$, hydroxyl radicals $(\mathrm{OH})$, peroxynitrite anion $\left(\mathrm{ONOO}^{-}\right)$and hydrogen peroxide $\left(\mathrm{H}_{2} \mathrm{O}_{2}\right)$, they can cause oxidative damage to the lipids, proteins, and nucleic acids of cells (González-Montero et al., 2018; Li et al.,
2018; Lei et al., 2019). To remove ROS, cells use intrinsic antioxidant defense systems, including antioxidative enzymes and antioxidants, such as superoxide dismutase (SOD), catalase (CAT), glutathione peroxidase (GPx), and glutathione, to protect against the injurious effects of excessive ROS (Finkel, 2003; Cai et al., 2017; González-Montero et al., 2018). Hyperglycemia (Rolo and Palmeira, 2006; Yang et al., 2015), hypoxia (Deng et al., 2017; Tang et al., 2018), ischemia or ischemia/reperfusion (I/R) (Yu et al., 2015; González-Montero et al., 2018), all induce oxidative stress.

Multiple miRs have been shown to be involved in the development of oxidative stress, this topic has been reviewed elsewhere (Magenta et al., 2013; Nikolai et al., 2018; Carbonell and Gomes, 2020), and the miRs that have been reported to regulate antioxidant system are listed in the latest review (Carbonell and Gomes, 2020). Some miRs can aggravate oxidative stress, whereas others have the opposite roles. For instance, the application of miR-223-3p inhibitor can alleviate hypoxia-induced oxidative stress and apoptosis (Tang et al., 2018), while miR-377 inhibitor can alleviate renal I/R-induced oxidative stress and inflammation (Liu et al., 2019b). Both miR27a (Zhao Y. et al., 2018) and miR-140-5p (Zhao L. et al., 2018) can exacerbate oxidative damage by down-regulation of the target Nrf2 (nuclear factor erythroid 2-related factor 2). Nrf2 is an important transcription factor which binds to the antioxidant response element (ARE) (Kensler et al., 2007), and regulates key genes involved in oxidative stress, such as SOD, CAT, heme oxygenase 1 (HO-1) and glutamate-cysteine ligase modifier subunit (GCLM), while Nrf2 expression is also regulated by its inhibitory protein called Kelch-like ECH-associated protein 1 (Keap1) and plays a critical role in promoting endogenous antioxidant capacity to combat ischemia-reperfusion injury induced oxidative stress and organ or tissue injuries (Gao et al., 2016; Han et al., 2016; Luo et al., 2019). By contrast, miR-7 can target Keap1 and activate Nrf2 pathway, therefore, it can relieve oxidative stress and exert cytoprotective effects by regulating the Nrf2 pathway (Kabaria et al., 2015). Several studies have reported that miR-503 is involved in oxidative stress (Miao et al., 2017; Rubattu et al., 2017; Chen et al., 2020; Zhang et al., 2020). In this section, we summarize and analyze the mechanisms of miR-503 in oxidative stress.

Myocardial I/R injury can lead to oxidative stress in both the experimental settings of myocardial I/R (Xia et al., 2003a; Xia et al., 2003b; Zhengyuan et al., 2005; Liu et al., 2011) and in patients undergoing open heart surgeries under cardiopulmonary bypass (Ansley et al., 2003; Xia et al., 2006; Huang et al., 2011). Varga et al., (2014) reported that miR-503 was downregulated in the isolated rat hearts subjected to $30 \mathrm{~min}$ of left anterior descending coronary artery ligation followed by $120 \mathrm{~min}$ of reperfusion, and ischemic postconditioning attenuated the downregulation of miR-503. However, the exact role of miR-503 in oxidative stress induced by $I / R$ has not been explored yet. In diabetic cardiomyopathy (DCM) (Miao et al., 2017), miR-503 was increased significantly in the rat heart tissues but decreased by Phase II enzyme inducer (CPDT) treatment. Nrf2 was proven as miR-503 target by luciferase assay, it was decreased in DCM but 
increased by CPDT treatment (Miao et al., 2017). It is suggested by Miao et al., (2017) that CPDT can alleviate oxidative stress in DCM through miR-503/Nrf2/ARE signaling pathway, while the authors did not simultaneously detect the oxidative stress markers in the presence of either the miR-503 mimic or an inhibitor of miR-503 in diabetic rats, nor in cultured cardiomyocytes exposed to high glucose mimicking the situation of diabetes. In human microvascular endothelial cells (Chen et al., 2020), miR-503 inhibitor alleviated HGinduced oxidative stress by the inactivation of JNK and p38 MAPK phosphorylation, suggesting that miR-503 has the property of pro-oxidative stress.

In spontaneous hypertension and stroke rat model (Rubattu et al., 2017), the miR-503 expression level was increased significantly in brains of Spontaneously Hypertensive Stroke Prone rats (SHRSP) upon high-salt diet, but reduced in brains of Spontaneously Hypertensive Stroke Resistant Rats (SHRSR). The peroxidation end products carbonylated total proteins were also increased markedly in brains of high-salt-fed SHRSP, but not in high-salt-fed SHRSR. In contrast, the mRNA and protein expression levels of uncoupling protein 2 (UCP2) were decreased significantly in brains of SHRSP upon high-salt diet, but not in brains of SHRSR. And overexpression of miR-503 in endothelial cells in vitro decreased UCP2 expression and increased cell mortality (Rubattu et al., 2017). It is indicated that the downregulation of UCP2 expression regulated by miR503 increases oxidative stress and stroke occurrence in high-saltfed SHRSR. UCP2 is a mitochondrial membrane protein and wildly expressed among organs (Mattiasson and Sullivan, 2006), and overexpression of UCP2 protected against endothelial dysfunction of vessels through reducing ROS production followed by increasing nitric oxide (NO) bioavailability (Tian et al., 2012). Another study reported that miR-503 expression level in plasma of patients with moderate and severe ischemic stroke was highest compared to patients with minor stroke and control individuals (Zhang et al., 2020). It is also demonstrated that overexpression of miR-503 increased cell apoptosis and ROS production, but reduced NO generation in vivo and in intro, while inhibition of miR503 alleviated apoptosis, oxidative stress, and increased NO generation by activation of PI3K/AKT/eNOS pathway, and it is indicated that plasma miR-53 may be an attractively diagnostic marker or therapeutic target for ischemic stroke (Zhang et al., 2020).

To summarize, the mechanisms of miR-503 in oxidative stress is not well understood especially in I/R injury or diabetes, it is worthy of further investigation.

\section{The Mechanisms of Abnormal miR-503 Expression in Cardiovascular Disease or Cancer}

Studies have shown that miR-503 is expressed abnormally in human diseases, such as diabetes (Caporali et al., 2011; Xu et al., 2017), pulmonary arterial hypertension, coronary artery disease (Fei et al., 2018), ischemic stroke (Zhang et al., 2020) and cancer, and have explored the roles of miR-503 in diseases by overexpressing or inhibiting miR-503 in vivo and in vitro. The

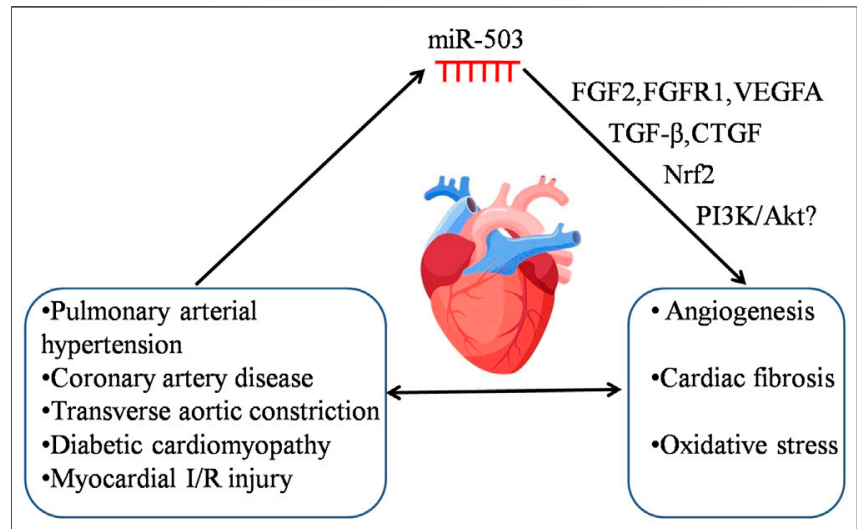

FIGURE 1| The potential mechanism of miR-503 in regulating cardiovascular disease. Cardiovascular disease induces the abnormal expression of miR-503. The dysregulation of miR-503 may contribute to various pathologies, e.g., angiogenesis, cardiac fibrosis and oxidative stress, and it would subsequently aggravate the severity of cardiovascular disease. The following targets, FGF2, FGFR1, VEGFA, TGF- $\beta$, CTGF, Nrf2, and PI3K/Akt may be involved in the pathological processes of cardiovascular disease regulated by miR- 503 .

potential mechanism of miR-503 in regulating cardiovascular disease is shown in Figure 1. However, the mechanisms of its abnormal expression in diseases are little known.

DNA methylation in the promoters of miRs or histone modifications have been evaluated for the dysregulation of miRs (Manel, 2011; Druz et al., 2012; Zhang et al., 2016). The mechanisms governing miR-503 down-regulation or its activation have been explored in few studies. On the one hand, several studies have reported the reasons of miR-503 downregulation. Zhou et al., (2013) and Hirakawa et al., (2016) have shown that the downregulation of miR-503 in HCC tissues or human endometriotic cyst stromal cells may be due to DNA hypermethylation near the promoter of miR503. Yan W. et al., (2017) reported that IncRNA MALAT1 bound to miR-503 directly as a sponge and downregulated miR-503 expression in silica-induced pulmonary fibrosis. In patients with acute MI and in rat model of myocardial I/R injury, MALAT1 was increased in peripheral blood cells (Vausort et al., 2014) or myocardial tissues (Sun T. et al., 2019). Our unpublished data and Varga et al.'s data (Varga et al., 2014) showed that miR-503 expression level was downregulated in myocardial tissues following I/R injury. However, it is yet to be determined whether or not the downregulation of miR-503 in myocardial I/R injury may be due to the upregulation of MALAT1 or DNA methylation. On the other hand, the mechanism governing the activation of miR-503 expression has also been explored. Kim et al., (Jongmin et al., 2012) demonstrated that overexpression of APLN (apelin) induced miR-424/503 expression by regulation of miR-424/503 promoter in pulmonary artery endothelial cells. Jiang et al., (2016) showed that miR-503 expression was activated by GATA3 binding to its promoter. Caporali et al., (2015) showed that NF- $\kappa B$ was activated by $p 75$ neurotrophin receptor (p75 ${ }^{\mathrm{NTR}}$ ) 
and bond to the promoter of miR-503, leading to miR-503 transcription in endothelial cells. Taken together, the mechanisms of miR-503 dysregulation are diverse and complicated in different pathological conditions. Further investigation of abnormal miR-503 expression is needed for discovering good therapeutic targets.

\section{CONCLUSION AND FUTURE DIRECTIONS}

miR-503 is extensively studied in cancer, and most studies reported that miR-503 acted as a tumor suppressor, while a few studies showed miR-503 may function as an "onco-miR". Whether overexpression or inhibition of miR-503 in vivo can suppress tumor growth depends on cancer types, and preclinical studies are still needed to address the impact of miR- 503 on the development of cancer. In the aspects of tissue fibrosis or oxidative stress, there are few studies of miR-503 and the mechanisms are little known. Cardiac fibrosis can occur following by MI, but it is unclear whether the role of miR-503 in TAC or MI induced cardiac fibrosis is similar. Oxidative stress is one of risk factors in myocardial I/R injury, the role of miR-503 in regulating oxidative stress in myocardial I/R injury is still unknown. To explore miR-503

\section{REFERENCES}

Ahmed, S. B., Tatsuya, A., Jian-Peng, T., Yao-Liang, T., and Il-Man, K. (2018). Circular noncoding RNAs as potential therapies and circulating biomarkers for cardiovascular diseases. Acta Pharmacol. Sinica 39 (7), 1100-1109. doi:10.1038/ aps.2017.196

Aisagbonhi, O., Rai, M., Ryzhov, S., Atria, N., Feoktistov, I., and Hatzopoulos, A. K. (2011). Experimental myocardial infarction triggers canonical Wnt signaling and endothelial-to-mesenchymal transition. Dis. Model. Mech. 4 (4), 469-483. doi:10.1242/dmm.006510

Alessandra, C., Daniele, C., Federica, F., Désirée, B., Antonio, A., Paolo, G., et al. (2007). MicroRNA-133 controls cardiac hypertrophy. Nat. Med. 13 (5), 613. doi: $10.1038 / \mathrm{nm} 1582$

Almeida, M. I., Nicoloso, M. S., Zeng, L., Ivan, C., Spizzo, R., Gafa, R., et al. (2012). Strand-specific miR-28-5p and miR-28-3p have distinct effects in colorectal cancer cells. Gastroenterology 142 (4), 886-889.e9. doi:10.1053/j.gastro.2011. 12.047

Ansley, D. M., Xia, Z., and Dhaliwal, B. S. (2003). The relationship between plasma free 15-F2t-isoprostane concentration and early postoperative cardiac depression following warm heart surgery. J. Thorac. Cardiovasc. Surg. 126 (4), 1222-1223. doi:10.1016/S0022-5223(03)00794-3

Bartel, D. P. (2004). MicroRNAs: genomics, biogenesis, mechanism, and function. Cell 116 (2), 281-297. doi:10.1016/S0092-8674(04)00045-5

Bi, R., Ding, F., He, Y., Jiang, L., Jiang, Z., Mei, J., et al. (2016). miR-503 inhibits platelet-derived growth factor-induced human aortic vascular smooth muscle cell proliferation and migration through targeting the insulin receptor. Biomed. Pharmacother. 84, 1711-1716. doi:10.1016/j. biopha.2016.10.081

Bonauer, A., Carmona, G., Iwasaki, M., Mione, M., Koyanagi, M., Fischer, A., et al. (2009). MicroRNA-92a controls angiogenesis and functional recovery of ischemic tissues in mice. Science 324 (5935), 1710. doi:10.1126/science. 1174381

Brennecke, J., Hipfner, D. R., Stark, A., Russell, R. B., and Cohen, S. M. (2003). Bantam encodes a developmentally regulated microRNA that controls cell proliferation and regulates the proapoptotic gene hid in Drosophila. Cell 113 (1), 25-36. doi:10.1016/S0092-8674(03)00231-9 as therapeutic target or diagnostic marker, further investigation can be focused on the role of miR-503 in tissue fibrosis or oxidative stress, and the dysregulation of miR-503 in cardiovascular disease, especially myocardial I/R injury deserves further investigation.

\section{AUTHOR CONTRIBUTIONS}

YH conceived the idea of the review. YH, YC, PP, XR, and ZX wrote and edited the review. All authors contributed to the article and approved the submitted version.

\section{FUNDING}

This work is supported by the General Research Fund (17158616), and Health and Medical Research Fund (05161826).

\section{ACKNOWLEDGMENTS}

We thank team members of the Xia laboratory for helpful support.

Cai, Y., Kandula, V., Kosuru, R., Ye, X., Irwin, M. G., and Xia, Z. (2017). Decoding telomere protein Rap1: its telomeric and nontelomeric functions and potential implications in diabetic cardiomyopathy. Cell Cycle 16 (19), 1765-1773. doi:10. 1080/15384101.2017.1371886

Cantley, L. C. (2002). The phosphoinositide 3-kinase pathway. Science 296 (5573), 1655-1657. doi:10.1126/science.296.5573.1655

Caporali, A., and Emanueli, C. (2009). Cardiovascular actions of neurotrophins. Bethesda, MD: American Physiological Society).

Caporali, A., and Emanueli, C. (2011). MicroRNA-503 and the extended microRNA-16 family in angiogenesis. Trends Cardiovasc. Med. 21 (6), 162-166. doi:10.1016/j.tcm.2012.05.003

Caporali, A., Meloni, M., Nailor, A., Mitić, T., Shantikumar, S., Riu, F., et al. (2015). p75(NTR)-dependent activation of NF- $\kappa B$ regulates microRNA-503 transcription and pericyte-endothelial crosstalk in diabetes after limb ischaemia. Nat. Commun. 6 (1, 8024). doi:10.1038/ncomms 9024

Caporali, A., Meloni, M., Völlenkle, C., Bonci, D., Sala-Newby, G. B., Addis, R. et al. (2011). Deregulation of microRNA-503 contributes to diabetes mellitusinduced impairment of endothelial function and reparative angiogenesis after limb ischemia. Circulation 123 (3), 282-291. doi:10.1161/ CIRCULATIONAHA.110.952325

Carbonell, T., and Gomes, A. V. (2020). MicroRNAs in the regulation of cellular redox status and its implications in myocardial ischemia-reperfusion injury. Redox Biol. 36, 101607. doi:10.1016/j.redox.2020.101607

Chang, S. W., Yue, J., Wang, B. C., and Zhang, X. L. (2015). miR-503 inhibits cell proliferation and induces apoptosis in colorectal cancer cells by targeting E2F3. Int. J. Clin. Exp. Pathol. 8 (10), 12853-12860.

Chen, C. Z., Li, L., Lodish, H. F., and Bartel, D. P. 2004). MicroRNAs modulate hematopoietic lineage differentiation. Science 303 (5654), 83-86. doi:10.1126/ science. 1091903

Chen, K., Zhao, X. L., Li, L. B., Huang, L. Y., Tang, Z., Luo, J., et al. (2020). miR-503/ Apelin-12 mediates high glucose-induced microvascular endothelial cells injury via JNK and p38MAPK signaling pathway. Regen. Ther. 14, 111-118. doi:10. 1016/j.reth.2019.12.002

Chen, Z., Chen, X., Chen, P., Yu, S., Nie, F., Lu, B., et al. (2017). Long non-coding RNA SNHG20 promotes non-small cell lung cancer cell proliferation and migration by epigenetically silencing of P21 expression. Cell Death Dis 8 (10), e3092. doi:10.1038/cddis.2017.484 
Chen, Z., Hu, Z., Lu, Z., Cai, S., Gu, X., Zhuang, H., et al. (2013). Differential microRNA profiling in a cellular hypoxia reoxygenation model upon posthypoxic propofol treatment reveals alterations in autophagy signaling network. Oxid. Med. Cell Longev., 2013, 378484-378511. doi:10.1155/2013/ 378484

Cheng, Y., and Liu, W. (2019). MicroRNA-503 serves an oncogenic role in retinoblastoma progression by directly targeting PTPN12. Exp. Ther. Med. 18 (3), 2285. doi:10.3892/etm.2019.7795

Christine, W., Dongtak, J., Agustin, R.-M., Changwon, K., Ahyoung, L., Shinichi, M., et al. (2014). Inhibition of miR-25 improves cardiac contractility in the failing heart. Nature 508 (7497), 531. doi:10.1038/nature13073

Couzin, J. (2008). MicroRNAs make big impression in disease after disease. Science 319 (5871), 1782-1784. doi:10.1126/science.319.5871.1782

Cremer, S., Michalik, K. M., Fischer, A., Pfisterer, L., Jaé, N., Winter, C., et al. (2019). Hematopoietic deficiency of the long noncoding RNA MALAT1 promotes atherosclerosis and plaque inflammation. Circulation 139 (10), 1320-1334. doi:10.1161/CIRCULATIONAHA.117.029015

Deng, F., Wang, S., Zhang, L., Xie, X., Cai, S., Li, H., et al. (2017). Propofol through upregulating caveolin-3 attenuates post-hypoxic mitochondrial damage and cell death in H9C2 cardiomyocytes during hyperglycemia. Cell. Physiol. Biochem. 44 (1), 279-292. doi:10.1159/000484680

Druz, A., Betenbaugh, M., and Shiloach, J. (2012). Glucose depletion activates mmu-miR-466h-5p expression through oxidative stress and inhibition of histone deacetylation. Nucleic Acids Res. 40 (15), 7291. doi:10.1093/nar/gks452

Faxon, D. P., Creager, M. A., Smith, S. C., Pasternak, R. C., Olin, J. W., Bettmann, M. A., et al. (2004). Atherosclerotic vascular disease conference: executive summary: atherosclerotic vascular disease conference proceeding for healthcare professionals from a special writing group of the American Heart Association. Circulation 109 (21), 2595-2604. doi:10.1161/01.CIR. 0000128517.52533.DB

Fei, Y., Hou, J., Xuan, W., Zhang, C., and Meng, X. (2018). The relationship of plasma miR-503 and coronary collateral circulation in patients with coronary artery disease. Life Sci. 207, 145-151. doi:10.1016/j.lfs.2018.06.001

Finkel, T. (2003). Oxidant signals and oxidative stress. Curr. Opin. Cell Biol. 15 (2), 247-254. doi:10.1016/S0955-0674(03)00002-4

Forrest, A. R., Kanamori-Katayama, M., Tomaru, Y., Lassmann, T., Ninomiya, N., Takahashi, Y., et al. (2009). Induction of microRNAs, mir-155, mir-222, mir424 and mir-503, promotes monocytic differentiation through combinatorial regulation. Leukemia 24 (2), 460. doi:10.1038/leu.2009.246

Fruman, D. A., Meyers, R. E., and Cantley, L. C. (1998). Phosphoinositide kinases. Annu. Rev. Biochem. 67, 481. doi:10.1146/annurev.biochem.67.1.481

Fu, Y., Meng, Y., Gu, X., Tian, S., Hou, X., and Ji, M. (2019). miR-503 expression is downregulated in cervical cancer and suppresses tumor growth by targeting AKT2. J. Cell Biochem. 120 (5), 8177-8184. doi:10.1002/jcb.28099

Gao, S., Yang, Z., Shi, R., Xu, D., Li, H., Xia, Z., et al. (2016). Diabetes blocks the cardioprotective effects of sevoflurane postconditioning by impairing Nrf2/ Brg1/HO-1 signaling. Eur. J. Pharmacol. 779, 111-121. doi:10.1016/j.ejphar. 2016.03.018

Gao, X., Xu, Y., Xu, B., Liu, Y., Cai, J., Liu, H. M., et al. (2012). Allopurinol attenuates left ventricular dysfunction in rats with early stages of streptozotocin-induced diabetes. Diabetes Metab. Res. Rev. 28 (5), 409-417. doi:10.1002/dmrr.2295

Ge, L., Cai, Y., Ying, F., Liu, H., Zhang, D., He, Y., et al. (2019). MiR-181c-5p exacerbates hypoxia/reoxygenation-induced cardiomyocyte apoptosis via targeting PTPN4. Oxid. Med. Cell Longev. 2019, 1. doi:10.1155/2019/1957920

Ge, Z. D., Lian, Q., Mao, X., and Xia, Z. (2019). Current status and challenges of NRF2 as a potential therapeutic target for diabetic cardiomyopathy. Int. Heart J. 60 (3), 512-520. doi:10.1536/ihj.18-476

Gerhard, M. S., Fabian, T., Elizabeth, A. N., Christina, G. K., Mary, E. S., Michael, K., et al. (2006). A brain-specific microRNA regulates dendritic spine development. Nature 439 (7074), 283. doi:10.1038/nature04367

González-Montero, J., Brito, R., Gajardo, A. I., and Rodrigo, R. (2018). Myocardial reperfusion injury and oxidative stress: therapeutic opportunities. World J. Cardiol. 10 (9), 74-86. doi:10.4330/wjc.v10.i9.74

Greten, F., Eckmann, L., Greten, T., Park, J., Li, Z., Egan, L., et al. (2004). IKKbeta links inflammation and tumorigenesis in a mouse model of colitis-associated cancer. Cell 118 (3), 285-296. doi:10.1016/j.cell.2004.07.013
Griffiths-Jones, S., Grocock, R., van Dongen, S., Bateman, A., and Enright, A. (2006). miRBase: microRNA sequences, targets and gene nomenclature. Nucleic Acids Res. 34, D140-D144. doi:10.1093/nar/gkj112

Griffiths-Jones, S., Saini, H. K., van Dongen, S., and Enright, A. J. (2008). miRBase: tools for microRNA genomics. Nucleic Acids Res. 36 (Database Issue), D154. doi:10.1093/nar/gkm952

Guo, P., Yu, Y., Li, H., Zhang, D., Gong, A., Li, S., et al. (2017). TGF-âl-induced miR-503 controls cell growth and apoptosis by targeting PDCD4 in glioblastoma cells. Sci. Rep. 7 (1), 11569. doi:10.1038/s41598-017-11885-8

Guo, Y., Wu, X.-Q., Zhang, C., Liao, Z.-X., Wu, Y., Xia, Z. Y., et al. (2010). Effect of indole-3-carbinol on ethanol-induced liver injury and acetaldehydestimulated hepatic stellate cells activation using precision-cut rat liver slices. Clin. Exp. Pharmacol. Physiol. 37 (12), 1107-1113. doi:10.1111/j. 1440-1681.2010.05450.x

Han, X., Yao, W., Liu, Z., Li, H., Zhang, Z. J., Hei, Z., et al. (2016). Lipoxin A4 preconditioning attenuates intestinal ischemia reperfusion injury through keap1/nrf2 pathway in a lipoxin A4 receptor independent manner. Oxid. Med. Cell Longev. 2016, 9303606-9303612. doi:10.1155/2016/9303606

Hanna, A., Humeres, C., and Frangogiannis, N. G. (2021). The role of Smad signaling cascades in cardiac fibrosis. Cell Signal. 77, 109826. doi:10.1016/j. cellsig.2020.109826

Heerboth, S., Housman, G., Leary, M., Longacre, M., Byler, S., Lapinska, K., et al. (2015). EMT and tumor metastasis. Clin. Transl. Med. 4 (1), 6-13. doi:10.1186/ s40169-015-0048-3

Heise, R., Stober, V., Cheluvaraju, C., Hollingsworth, J. W., and Garantziotis, S. (2011). Mechanical stretch induces epithelial-mesenchymal transition in alveolar epithelia via hyaluronan activation of innate immunity. J. Biol. Chem. 286 (20), 17435-17444. doi:10.1074/jbc.M110.137273

Hirakawa, T., Nasu, K., Abe, W., Aoyagi, Y., Okamoto, M., Kai, K., et al. (2016). miR-503, a microRNA epigenetically repressed in endometriosis, induces apoptosis and cell-cycle arrest and inhibits cell proliferation, angiogenesis, and contractility of human ovarian endometriotic stromal cells. Hum. Reprod. 31 (11), 2587-2597. doi:10.1093/humrep/dew217

Huang, Z., Zhong, X., Irwin, M. G., Ji, S., Wong, G. T., Liu, Y., et al. (2011). Synergy of isoflurane preconditioning and propofol postconditioning reduces myocardial reperfusion injury in patients. Clin. Sci. 121 (2), 57-69. doi:10. 1042/CS20100435

Jiang, X., Chen, Y., Du, E., Yang, K., Zhang, Z., Qi, S., et al. (2016). GATA3-driven expression of miR-503 inhibits prostate cancer progression by repressing ZNF217 expression. Cell Signal. 28 (9), 1216-1224. doi:10.1016/j.cellsig.2016. 06.002

Joacim, E., Morten, L., Sylvia, S., Matthew, L., Andreas, P., Susanna, O., et al. (2008). LNA-mediated microRNA silencing in non-human primates. Nature 452 (7189), 896. doi:10.1038/nature06783

Jongmin, K., Yujung, K., Yoko, K., Janet, K. L., Xiaoyue, H., Micheala, A. A., et al. (2012). An endothelial apelin-FGF link mediated by miR-424 and miR-503 is disrupted in pulmonary arterial hypertension. Nat. Med. 19 (1), 74. doi:10.1038/ nm.3040

Jun, I., Amy, J. N., Jannah, O., Alvaro, G.-M., Kumiko, I., Fumihiko, M., et al. (2017). Reduced microRNA-503 expression augments lung fibroblast VEGF production in chronic obstructive pulmonary disease. PLoS One 12 (9), e0184039. doi:10.1371/journal.pone.0184039

Kabaria, S., Choi, D. C., Chaudhuri, A. D., Jain, M. R., Li, H., and Junn, E. (2015) MicroRNA-7 activates Nrf2 pathway by targeting Keap1 expression. Free Radic. Biol. Med. 89, 548-556. doi:10.1016/j.freeradbiomed.2015.09.010

Kalluri, R., and Weinberg, R. (2009). "The basics of epithelial-mesenchymal transition, J. Clin. Invest., 119, 1420. doi:10.1172/JCI39104

Keighron, C., Lyons, C. J., Creane, M., O’Brien, T., and Liew, A. (2018). Recent advances in endothelial progenitor cells toward their use in clinical translation. Front. Med. (Lausanne) 5, 354. doi:10.3389/fmed.2018.00354

Kensler, T. W., Wakabayashi, N., and Biswal, S. (2007). Cell survival responses to environmental stresses via the Keap1-Nrf2-ARE pathway Annu. Rev. Pharmacol. Toxicol. 47 (1), 89-116. doi:10.1146/annurev.pharmtox.46. 120604.141046

Kim, K. K., Kugler, M. C., Wolters, P. J., Robillard, L., Galvez, M. G., Brumwell, A. N., et al. (2006). Alveolar epithelial cell mesenchymal transition develops in vivo during pulmonary fibrosis and is regulated by the extracellular matrix. Proc. Natl. Acad. Sci. U.S.A. 103 (35), 13180-13185. doi:10.1073/pnas.0605669103 
Klimczak, D., Kuch, M., Pilecki, T., Żochowska, D., Wirkowska, A., and Pączek, L. (2017). Plasma microRNA-155-5p is increased among patients with chronic kidney disease and nocturnal hypertension. J. Am. Soc. Hypertens. 11 (12), 831-841.e834. doi:10.1016/j.jash.2017.10.008

Kreis, N.-N., Louwen, F., and Yuan, J. (2019). The multifaceted p21 (Cip1/Waf1/ CDKN1A) in cell differentiation, migration and cancer therapy. Cancers 11 (9), 1220. doi:10.3390/cancers 11091220

Lankat-Buttgereit, B., and Göke, R. (2009). The tumour suppressor Pdcd4: recent advances in the elucidation of function and regulation. Biol. Cell 101 (6), 309-317. doi:10.1042/BC20080191

Lei, S., Su, W., Xia, Z. Y., Wang, Y., Zhou, L., Qiao, S., et al. (2019). Hyperglycemiainduced oxidative stress abrogates remifentanil preconditioning-mediated cardioprotection in diabetic rats by impairing caveolin-3-modulated PI3K/ akt and JAK2/STAT3 signaling. Oxid. Med. Cell Longev. 2019, 9836302-9836319. doi:10.1155/2019/9836302

Lewis, B. P., Burge, C. B., and Bartel, D. P. (2005). Conserved seed pairing, often flanked by adenosines, indicates that thousands of human genes are MicroRNA targets. Cell 120 (1), 15-20. doi:10.1016/j.cell.2004.12.035

Li, H., Yao, W., Irwin, M. G., Wang, T., Wang, S., Zhang, L., et al. (2015). Adiponectin ameliorates hyperglycemia-induced cardiac hypertrophy and dysfunction by concomitantly activating Nrf2 and Brg1. Free Radic. Biol. Med. 84, 311-321. doi:10.1016/j.freeradbiomed.2015.03.007

Li, H., Xia, Z., Chen, Y., Qi, D., and Zheng, H. (2018). Mechanism and therapies of oxidative stress-mediated cell death in ischemia reperfusion injury. Oxid. Med. Cell Longev. 2018, 1-2. doi:10.1155/2018/2910643

Li, M., Luan, F., Zhao, Y., Hao, H., Zhou, Y., Han, W., et al. (2016). Epithelialmesenchymal transition: an emerging target in tissue fibrosis. Exp. Biol. Med. 241, 1-13. doi:10.1177/1535370215597194

Li, W., Li, J., Mu, H., Guo, M., and Deng, H. (2019). MiR-503 suppresses cell proliferation and invasion of gastric cancer by targeting HMGA2 and inactivating WNT signaling pathway. Cancer Cell Int. 19 (1), 164. doi:10. 1186/s12935-019-0875-1

Li, Y., Cai, B., Shen, L., Dong, Y., Lu, Q., Sun, S., et al. (2017). MiRNA-29b suppresses tumor growth through simultaneously inhibiting angiogenesis and tumorigenesis by targeting Akt3. Cancer Lett. 397, 111-119. doi:10.1016/j. canlet.2017.03.032

Li, Y., Li, W., Ying, Z., Tian, H., Zhu, X., Li, J., et al. (2014). Metastatic heterogeneity of breast cancer cells is associated with expression of a heterogeneous TGF $\beta$ activating miR424-503 gene cluster. Cancer Res. 74 (21), 6107-6118. doi:10. 1158/0008-5472.CAN-14-0389

Liu, G., Friggeri, A., Yang, Y., Milosevic, J., Ding, Q., Thannickal, V. J., et al. (2010). miR-21 mediates fibrogenic activation of pulmonary fibroblasts and lung fibrosis. J. Exp. Med. 207 (2), 1589-1597. doi:10.1084/jem.20100035

Liu, H. M., Liu, K. X., Cheng, M. H., Liu, Y., Lei, S., Irwin, M. G., et al. (2011). Bosentan affects 15-F2t-isoprostane adverse effects on postischemic rat hearts. J. Surg. Res. 168 (1), 18-26. doi:10.1016/j.jss.2009.07.029

Liu, Y., Baumgardt, S. L., Fang, J., Shi, Y., Qiao, S., Bosnjak, Z. J., et al. (2017). Transgenic overexpression of GTP cyclohydrolase 1 in cardiomyocytes ameliorates post-infarction cardiac remodeling. Sci. Rep. 7 (1), 3093-3015. doi:10.1038/s41598-017-03234-6

Liu, Y., Luo, F., Wang, B., Li, H., Xu, Y., Liu, X., et al. (2016). STAT3-regulated exosomal miR-21 promotes angiogenesis and is involved in neoplastic processes of transformed human bronchial epithelial cells. Cancer Lett. 370 (1), 125-135. doi:10.1016/j.canlet.2015.10.011

Liu, Y., Paterson, M., Baumgardt, S. L., Irwin, M. G., Xia, Z., Bosnjak, Z. J., et al. (2019a). Vascular endothelial growth factor regulation of endothelial nitric oxide synthase phosphorylation is involved in isoflurane cardiac preconditioning. Cardiovasc. Res. 115 (1), 168-178. doi:10.1093/cvr/cvy157

Liu, Z., Xu, S., Ji, Z., Xu, H., Zhao, W., Xia, Z., et al. (2020a). Mechanistic study of mtROS-JNK-SOD2 signaling in bupivacaine-induced neuron oxidative stress. Aging (Albany NY) 12 (13), 13463-13476. doi:10.18632/aging.103447

Liu, Z., Yang, Q., Wei, Q., Chang, Y., Qu, M., and Yu, L. (2019b). The protective effect of miR-377 inhibitor against renal ischemia-reperfusion injury through inhibition of inflammation and oxidative stress via a VEGF-dependent mechanism in mice. Mol. Immunol. 106, 153-158. doi:10.1016/j.molimm.2018.12.028

Liu, Z., Zhao, W., Yuan, P., Zhu, P., Fan, K., Xia, Z., et al. (2020b). The mechanism of CaMK2 $\alpha-M C U-m i t o c h o n d r i a l$ oxidative stress in bupivacaine-induced neurotoxicity. Free Radic. Biol. Med. 152, 363-374. doi:10.1016/j. freeradbiomed.2020.04.002

Long, J., Ou, C., Xia, H., Zhu, Y., and Liu, D. (2015). MiR-503 inhibited cell proliferation of human breast cancer cells by suppressing CCND1 expression. Tumour Biol. 36 (11), 8697-8702. doi:10.1007/s13277-015-3623-8

Luo, J., Yan, D., Li, S., Liu, S., Zeng, F., Cheung, C. W., et al. (2020). Allopurinol reduces oxidative stress and activates $\mathrm{Nrf} 2 / \mathrm{p} 62$ to attenuate diabetic cardiomyopathy in rats. J. Cell Mol. Med. 24 (2), 1760-1773. doi:10.1111/ jcmm. 14870

Magenta, A., Greco, S., Gaetano, C., and Martelli, F. (2013). Oxidative stress and microRNAs in vascular diseases. Int. J. Mol. Sci. 14 (9), 17319-17346. doi:10. 3390/ijms140917319

Manel, E. (2011). Non-coding RNAs in human disease. Nat. Rev. Genet. 12 (12), 861. doi:10.1038/nrg3074

Manu, K., Cao, P., Chai, T., Casey, P., and Wang, M. (2019). p21cip1/waf1 coordinates autophagy, proliferation and apoptosis in response to metabolic stress. Cancers 11 (8), 1112. doi:10.3390/cancers 11081112

Mattiasson, G., and Sullivan, P. G. (2006). The emerging functions of UCP2 in health, disease, and therapeutics. Antioxid. Redox Signal. 8 (1-2), 1-38. doi:10. 1089/ars.2006.8.1

Miao, Y., Wan, Q., Liu, X., Wang, Y., Luo, Y., Liu, D., et al. (2017). miR-503 is involved in the protective effect of phase II enzyme inducer (CPDT) in diabetic cardiomyopathy via Nrf2/ARE signaling pathway. Biomed. Res. Int. 2017, 1. doi:10.1155/2017/9167450

Min, S., Liang, X., Zhang, M., Zhang, Y., Mei, S., Liu, J., et al. (2013). Multiple tumor-associated microRNAs modulate the survival and longevity of dendritic cells by targeting YWHAZ and Bcl2 signaling pathways. J. Immunol. 190 (5), 2437. doi:10.4049/jimmunol.1202282

Nie, Y., Han, B. M., Liu, X. B., Yang, J. J., Wang, F., Cong, X. F., et al. (2011). Identification of microRNAs involved in hypoxia- and serum deprivationinduced apoptosis in mesenchymal stem cells. Int. J. Biol. Sci. 7 (6), 762-768. doi:10.7150/ijbs.7.762

Nikolai, E., Eva, Ž., Alexander, R., Francesco, G., Fabiola, O., Antonio Domenico, P., et al. (2018). From oxidative stress damage to pathways, networks, and autophagy via microRNAs. Oxid. Med. Cell Longev. 2018. doi:10.1155/2018/ 4968321

Noguchi, T., Toiyama, Y., Kitajima, T., Imaoka, H., Hiro, J., Saigusa, S., et al. (2016). miRNA-503 promotes tumor progression and is associated with early recurrence and poor prognosis in human colorectal cancer. Oncology 90 (4), 221. doi: $10.1159 / 000444493$

O'Brien, J., Brien, H., Zayed, Y., Peng, C., and Peng, C. (2018). Overview of MicroRNA biogenesis, mechanisms of actions, and circulation. Front. Endocrinol. (Lausanne) 9, 402. doi:10.3389/fendo.2018.00402

Osaki, M., Oshimura, M., and Ito, H. (2004). PI3K-Akt pathway: its functions and alterations in human cancer. Apoptosis 9 (6), 667-676. doi:10.1023/B:APPT. 0000045801.15585.dd

Özata, D. M., Caramuta, S., Velázquez-Fernández, D., Akçakaya, P., Xie, H., Höög, A., et al. (2011). The role of microRNA deregulation in the pathogenesis of adrenocortical carcinoma. Endocr. Relat. Cancer 18 (6), 643-655. doi:10.1530/ ERC-11-0082

Pan, Z., Sun, X., Shan, H., Wang, N., Wang, J., Ren, J., et al. (2012). MicroRNA-101 inhibited postinfarct cardiac fibrosis and improved left ventricular compliance via the FBJ osteosarcoma oncogene/transforming growth factor- $\beta 1$ pathway. Circulation 126 (7), 840-850. doi:10.1161/ CIRCULATIONAHA.112.094524

Peter, C., and Rakesh, K. J. (2011). Molecular mechanisms and clinical applications of angiogenesis. Nature 473 (7347), 298. doi:10.1038/nature10144

Rolo, A. P., and Palmeira, C. M. (2006). Diabetes and mitochondrial function: role of hyperglycemia and oxidative stress. Toxicol. Appl. Pharmacol. 212 (2), 167-178. doi:10.1016/j.taap.2006.01.003

Rubattu, S., Stanzione, R., Bianchi, F., Cotugno, M., Forte, M., Della Ragione, F., et al. (2017). Reduced brain UCP2 expression mediated by microRNA-503 contributes to increased stroke susceptibility in the high-salt fed stroke-prone spontaneously hypertensive rat. Cell Death Dis. 8 (6), e2891. doi:10.1038/cddis. 2017.278

Ruijtenberg, S., and van Den Heuvel, S. (2016). Coordinating cell proliferation and differentiation: antagonism between cell cycle regulators and cell type-specific 
gene expression. Cell Cycle 15 (2), 196-212. doi:10.1080/15384101.2015. 1120925

Sarkar, S., Dey, B. K., Dutta, A., and Solomon, M. J. (2010). MiR-322/424 and -503 are induced during muscle differentiation and promote cell cycle quiescence and differentiation by down-regulation of Cdc25A. Mol. Biol. Cell 21 (13), 2138-2149. doi:10.1091/mbc.E10-01-0062

Sheikhbahaei, S., Manizheh, D., Mohammad, S., Hasan, T. M., Saman, N., Laleh, R., et al. (2019). Can MiR-503 be used as a marker in diabetic patients with ischemic stroke? BMC Endocr. Disord. 19 (1), 42. doi:10.1186/s12902-019-0371-6

Shen, X., Soibam, B., Benham, A., Xu, X., Chopra, M., Peng, X., et al. (2016). miR$322 /-503$ cluster is expressed in the earliest cardiac progenitor cells and drives cardiomyocyte specification. Proc. Natl. Acad. Sci. U.S.A. 113 (34), 9551. doi:10. 1073/pnas. 1608256113

Simion, C., Cedano-Prieto, M. E., and Sweeney, C. (2014). The LRIG family: enigmatic regulators of growth factor receptor signaling. Endocr. Relat. Cancer 21 (6), R431-R443. doi:10.1530/ERC-14-0179

Singh, N., Promkan, M., Liu, G., Varani, J., and Chakrabarty, S. (2013). Role of calcium sensing receptor (CaSR) in tumorigenesis. Best Pract. Res. Clin. Endocrinol. Metab. 27 (3), 455-463. doi:10.1016/j.beem.2013.04.001

Sommariva, E., D’Alessandra, Y., Farina, F. M., Casella, M., Cattaneo, F., Catto, V., et al. (2017). MiR-320a as a potential novel circulating biomarker of arrhythmogenic cardioMyopathy. Sci. Rep. 7 (1), 4802-4810. doi:10.1038/ s41598-017-05001-Z

Sun, S., Shu, Y., and Tao, M. (2019). miR-503 inhibits proliferation, migration, and angiogenesis of glioma by acting on VEGFA through targeting LRIG2. Cancer Manag. Res. 11, 10599-10608. doi:10.2147/CMAR.S222681

Sun, Y., Li, L., Xing, S., Pan, Y., Shi, Y., Zhang, L., et al. (2017). miR-503-3p induces apoptosis of lung cancer cells by regulating p21 and CDK4 expression. Cancer Biomark. 20 (4), 597-608. doi:10.3233/CBM-170585

Sun, T., Cheng, Y.-T., Yan, L. X., Krittanawong, C., Qian, W., and Zhang, H. J. (2019). LncRNA MALAT1 knockdown alleviates myocardial apoptosis in rats with myocardial ischemia-reperfusion through activating PI3K/AKT signaling pathway. Eur. Rev. Med. Pharmacol. Sci. 23 (23), 10523-10531. doi:10.26355/ eurrev_201912_19693

Tang, Q., Li, M. Y., Su, Y. F., Fu, J., Zou, Z. Y., Wang, Y., et al. (2018). Absence of miR-223-3p ameliorates hypoxia-induced injury through repressing cardiomyocyte apoptosis and oxidative stress by targeting KLF15. Eur. J. Pharmacol. 841, 67-74. doi:10.1016/j.ejphar.2018.10.014

Tian, X. Y., Wong, W. T., Xu, A., Lu, Y., Zhang, Y., Wang, L., et al. (2012). Uncoupling protein-2 protects endothelial function in diet-induced obese mice. Circ. Res. 110 (9), 1211-1216. doi:10.1161/CIRCRESAHA.111.262170

Tognon, C. E., and Sorensen, P. H. (2012). Targeting the insulin-like growth factor 1 receptor (IGF1R) signaling pathway for cancer therapy. Expert Opin. Ther. Targets. 16 (1), 33-48. doi:10.1517/14728222.2011.638626

Tsai, G. Y., Cui, J. Z., Syed, H., Xia, Z., Ozerdem, U., McNeill, J. H., et al. (2009). Effect of $\mathrm{N}$-acetylcysteine on the early expression of inflammatory markers in the retina and plasma of diabetic rats. Clin. Exp. Ophthalmol. 37 (2), 223-231. doi:10.1111/j.1442-9071.2009.02000.x

Varga, Z., Zvara, A., Faragó, N., Kocsis, G., Pipicz, M., Gáspár, R., et al. (2014). MicroRNAs associated with ischemia-reperfusion injury and cardioprotection by ischemic pre- and postconditioning: protectomiRs. Am. J. Physiol. Heart Circ. Physiol. 307 (2), H216. doi:10.1152/ajpheart.00812.2013

Vausort, M., Wagner, D. R., and Devaux, Y. (2014). Long noncoding RNAs in patients with acute myocardial infarction. Circ. Res. 115 (7), 668-677. doi:10. 1161/circresaha.115.303836

Wang, F., Long, G., Zhao, C., Li, H., Chaugai, S., Wang, Y., et al. (2013). Plasma microRNA-133a is a new marker for both acute myocardial infarction and underlying coronary artery stenosis. J. Transl Med. 11 (1), 222. doi:10.1186/ 1479-5876-11-222

Wang, W. X., Rajeev, B. W., Stromberg, A. J., Ren, N., Tang, G., Huang, Q., et al. (2008). The expression of microRNA miR-107 decreases early in Alzheimer's disease and may accelerate disease progression through regulation of beta-site amyloid precursor protein-cleaving enzyme 1. J. Neurosci. 28 (5), 1213-1223. doi:10.1523/jneurosci.5065-07.2008

Wang, Z., Zheng, C., Jiang, K., He, J., Cao, X., and Wu, S. (2017). MicroRNA-503 suppresses cell proliferation and invasion in osteosarcoma via targeting insulinlike growth factor 1 receptor. Exp. Ther. Med. 14 (2), 1547-1553. doi:10.3892/ etm. 2017.4648
Warisara, P., Theerut, L., Supachoke, M., and Hitoshi, K. (2020). Therapeutic targets for the treatment of cardiac fibrosis and cancer: focusing on TGF- $\beta$ signaling. Front. Cardiovasc. Med. 7, 34. doi:10.3389/fcvm.2020.00034

Watanabe, G., Pena, P., Shambaugh, G. E., Haines, G. K., and Pestell, R. G. (1998). Regulation of cyclin dependent kinase inhibitor proteins during neonatal cerebella development. Brain Res. Dev. Brain Res. 108 (1-2), 77-87. doi:10. 1016/S0165-3806(98)00032-7

Wen, Y., Chen, R., Zhu, C., Qiao, H., Liu, Y., Ji, H., et al. (2018). MiR-503 suppresses hypoxia-induced proliferation, migration and angiogenesis of endothelial progenitor cells by targeting Apelin. Peptides 105, 58-65. doi:10. 1016/j.peptides.2018.05.008

Wu, J., Gao, F., Xu, T., Deng, X., Wang, C., Yang, X., et al. (2018). miR-503 suppresses the proliferation and metastasis of esophageal squamous cell carcinoma by triggering autophagy via $\mathrm{PKA} / \mathrm{mTOR}$ signaling. Int. J. Oncol. 52, 1427-1442. doi:10.3892/ijo.2018.4320

Wysocka, M. B., Pietraszek-Gremplewicz, K., and Nowak, D. (2018). The role of apelin in cardiovascular diseases, obesity and cancer. Front. Physiol. 9, 557. doi:10.3389/fphys.2018.00557

Xia, Z., Godin, D. V., and Ansley, D. M. (2003a). Propofol enhances ischemic tolerance of middle-aged rat hearts: effects on $15-\mathrm{F}(2 \mathrm{t})$-isoprostane formation and tissue antioxidant capacity. Cardiovasc. Res. 59 (1), 113. doi:10.1016/s00086363(03)00351-1

Xia, Z., Godin, D. V., Chang, T. K., and Ansley, D. M. (2003b). Dose-dependent protection of cardiac function by propofol during ischemia and early reperfusion in rats: effects on 15-F2t-isoprostane formation. Can. J. Physiol. Pharmacol. 81 (1), 14-21. doi:10.1139/y02-170

Xia, Z., Kuo, K. H., Nagareddy, P. R., Wang, F., Guo, Z., Guo, T., et al. (2007). $\mathrm{N}$-acetylcysteine attenuates PKCbeta2 overexpression and myocardial hypertrophy in streptozotocin-induced diabetic rats. Cardiovasc. Res. 73 (4), 770-782. doi:10.1016/j.cardiores.2006.11.033

Xia, M. Z., Huang, M. Z., and Ansley, M. D. (2006). Large-dose propofol during cardiopulmonary bypass decreases biochemical markers of myocardial injury in coronary surgery patients: a comparison with isoflurane. Anesthes. Analges. 10 (3), 527-532. doi:10.1213/01.ane.0000230612.29452.a6

Xiao, F., Zhang, W., Chen, L., Chen, F., Xie, H., Xing, C., et al. (2013). MicroRNA503 inhibits the G1/S transition by downregulating cyclin D3 and E2F3 in hepatocellular carcinoma. J. Transl. Med. 11 (1), 195. doi:10.1186/1479-587611-195

Xu, K., Bian, D., Hao, L., Huang, F., Xu, M., Qin, J., et al. (2017). microRNA-503 contribute to pancreatic $\beta$ cell dysfunction by targeting the mTOR pathway in gestational diabetes mellitus. EXCLI $J$ 16, 1177-1187. doi:10.17179/ excli2017-738

Yan, J., Xu, Y., Wang, H., Du, T., and Chen, H. (2017). MicroRNA-503 inhibits the proliferation and invasion of breast cancer cells via targeting insulin-like growth factor 1 receptor. Mol. Med. Rep. 16 (2), 1707. doi:10. 3892/mmr.2017.6816

Yan, W., Wu, Q., Yao, W., Li, Y., Liu, Y., Yuan, J., et al. (2017). MiR-503 modulates epithelial-mesenchymal transition in silica-induced pulmonary fibrosis by targeting PI3K p85 and is sponged by lncRNA MALAT1. Sci. Rep. 7 (1), 11313. doi:10.1038/s41598-017-11904-8

Yan, Z., Wang, H., Liang, J., Li, Y., and Li, X. (2020). MicroRNA-503-5p improves carotid artery stenosis by inhibiting the proliferation of vascular smooth muscle cells. Exp. Ther. Med. 20 (5), 1. doi:10.3892/etm.2020.9213

Yang, H. K., Chen, H., Mao, F., Xiao, Q. G., Xie, R. F., and Lei, T. (2017). Downregulation of LRIG2 expression inhibits angiogenesis of glioma via EGFR/VEGF-A pathway. Oncol. Lett. 14 (4), 4021-4028. doi:10.3892/ol. 2017.6671

Yang, L., Liu, G., Li, X., Xia, Z., Wang, Y., Lin, W., et al. (2020). Small GTPase RAB6 deficiency promotes alveolar progenitor cell renewal and attenuates PM2.5induced lung injury and fibrosis. Cell Death Dis. 11 (10), 827. doi:10.1038/ s41419-020-03027-2

Yang, P., Reece, E. A., Wang, F., and Gabbay-Benziv, R. (2015). Decoding the oxidative stress hypothesis in diabetic embryopathy through proapoptotic kinase signaling. Am. J. Obstet. Gynecol. 212 (5), 569-579. doi:10.1016/j. ajog.2014.11.036

Yang, Y., Liu, L., Zhang, Y., Guan, H., Wu, J., Zhu, X., et al. (2014). MiR-503 targets PI3K p 85 and IKK- $\beta$ and suppresses progression of non-small cell lung cancer. Int. J. Cancer 135 (7), 1531-1542. doi:10.1002/ijc.28799 
Yu, X., Chi, X., Wu, S., Jin, Y., Yao, H., Wang, Y., et al. (2015). Dexmedetomidine pretreatment attenuates kidney injury and oxidative stress during orthotopic autologous liver transplantation in rats. Oxid. Med. Cell Longev., 2016, 4675817-4675810. doi:10.1155/2016/4675817

Zha, F., Bai, L., Tang, B., Li, J., Wang, Y., Zheng, P., et al. (2019). MicroRNA-503 contributes to podocyte injury via targeting E2F3 in diabetic nephropathy. J. Cell Biochem. 120 (8), 12574-12581. doi:10.1002/jcb.28524

Zhang, D., Lee, H., Cao, Y., Dela Cruz, C. S., and Jin, Y. (2016). miR-185 mediates lung epithelial cell death after oxidative stress. Am. J. Physiol. Lung Cell Mol. Physiol 310 (7), L700-L710. doi:10.1152/ajplung.00392.2015

Zhang, H., Pan, Q., Xie, Z., Chen, Y., Wang, J., Bihl, J., et al. (2020). Implication of MicroRNA503 in brain endothelial cell function and ischemic stroke. Transl. Stroke Res. 11 (5), 1148-1164. doi:10.1007/s12975-020-00794-0

Zhang, Y., Chen, X., Lian, H., Liu, J., Zhou, B., Han, S., et al. (2014). MicroRNA-503 acts as a tumor suppressor in glioblastoma for multiple antitumor effects by targeting IGF-1R. Oncol. Rep. 31 (3), 1445. doi:10.3892/or.2013.2951

Zhang, Y., and Yan, B. (2012). Cell cycle regulation by carboxylated multiwalled carbon nanotubes through p53-independent induction of p21 under the control of the BMP signaling pathway. Chem. Res. Toxicol. 25 (6), 1212-1221. doi:10.1021/tx300059m

Zhao, J. J., Yang, J., Lin, J., Yao, N., Zhu, Y., Zheng, J., et al. (2009). Identification of miRNAs associated with tumorigenesis of retinoblastoma by miRNA microarray analysis. Childs Nerv. Syst. 25 (1), 13-20. doi:10.1007/s00381-008-0701-x

Zhao, L., Qi, Y., Xu, L., Tao, X., Han, X., Yin, L., et al. (2018). MicroRNA-140-5p aggravates doxorubicin-induced cardiotoxicity by promoting myocardial oxidative stress via targeting Nrf2 and Sirt2. Redox Biol. 15 (C), 284-296. doi:10.1016/j.redox.2017.12.013

Zhao, Y., Dong, D., Reece, E. A., Wang, A. R., and Yang, P. (2018). Oxidative stressinduced miR-27a targets the redox gene nuclear factor erythroid 2-related factor 2 in diabetic embryopathy. Am. J. Obstet. Gynecol. 218 (1), 136.e110. doi:10.1016/j.ajog.2017.10.040

Zhao, Z., Fan, X., Jiang, L., Xu, Z., Xue, L., Zhan, Q., et al. (2017). miR-503-3p promotes epithelial-mesenchymal transition in breast cancer by directly targeting SMAD2 and E-cadherin. J. Genet. Genomics 44 (2), 75-84. doi:10. 1016/j.jgg.2016.10.005

Zhengyuan, X., Kuo-Hsing, K., David, V. G., Michael, J. W., Michelle, C. Y. T., and David, M. A. (2005). 15-F2t-isoprostane exacerbates myocardial ischemiareperfusion injury of isolated rat hearts. Am. J. Physiol. - Heart Circulat. Physiol. 289 (4), 1366-1372. doi:10.1152/ajpheart.00042.2005

Zhou, B., Ma, R., Si, W., Li, S., Xu, Y., Tu, X., et al. (2013). MicroRNA-503 targets FGF2 and VEGFA and inhibits tumor angiogenesis and growth. Cancer Lett. 333 (2), 159-169. doi:10.1016/j.canlet.2013.01.028

Zhou, Y., Deng, L., Zhao, D., Chen, L., Yao, Z., Guo, X., et al. (2016). MicroRNA503 promotes angiotensin II-induced cardiac fibrosis by targeting Apelin-13. J. Cell Mol. Med. 20 (3), 495-505. doi:10.1111/jcmm.12754

Conflict of Interest: The authors declare that the research was conducted in the absence of any commercial or financial relationships that could be construed as a potential conflict of interest.

Copyright (C) $2021 \mathrm{He}$, Cai, Pai, Ren and Xia. This is an open-access article distributed under the terms of the Creative Commons Attribution License (CC $B Y)$. The use, distribution or reproduction in other forums is permitted, provided the original author(s) and the copyright owner(s) are credited and that the original publication in this journal is cited, in accordance with accepted academic practice. No use, distribution or reproduction is permitted which does not comply with these terms. 


\section{GLOSSARY}

ARE antioxidant response element

Bcl-2 B-cell lymphoma/leukemia-2

CTGF connective tissue growth factor

CAD coronary artery disease

CAS Carotid artery stenosis

CC cervical cancer

CCC coronary collateral circulation

BMDCs bone marrow-derived dendritic cells

cdc25A cell division cycle $25 \mathrm{~A}$

COPD chronic obstructive pulmonary disease

CRC colorectal cancer

cdk2 cyclin-dependent-kinase 2

DCM diabetic cardiomyopathy

ESCC esophageal squamous cell carcinoma

EMT epithelial-mesenchymal transition

EPCs epithelial-mesenchymal transition

ECSCs endothelial progenitor cells

E2F3 E2F transcription factor 3
FGF2 fibroblast growth factor-b

FGFR1 FGF receptor

GBM glioblastoma multiforme

GC gastric cancer

HG high glucose

HMEC human microvascular endothelial cells

HCC hepatocellular carcinomas

IGF-1R Insulin-like growth factor 1 receptor

I/R Ischemia/Reperfusion

LRIG2 Leucine-rich repeats and immunoglobulin-like domains protein 2 miRs microRNAs

MI myocardial infarction

nt nucleotides

NSCLC non-small cell lung cancer

ROS reactive oxygen species

SMCs smooth muscle cells

TGF- $\boldsymbol{\beta}$ transforming growth factor beta

TAC transverse aortic constriction

UCP2 uncoupling protein 2

VEGFA vascular endothelial growth factor A 